\title{
The validity of laboratory flume data for predicting beach slopes of thickened tailings deposits
}

\author{
A.B. Fourie The University of Western Australia, Australia \\ S.K.Y. Gawu Kwame-Nkrumah University of Science and Technology, Ghana
}

\begin{abstract}
One method for the placement of thickened tailings is the central discharge technique. The beach slopes achieved with this method have generally been in the order of 2 to 3\%. With such small beach slopes, it is important to be able to predict the slope angles accurately. This is often done using laboratory flume tests. However, these predictions have tended to overestimate slope angles. This paper presents a model that takes account of the wall friction in flume tests and illustrates the folly of using flume tests indiscriminately. The model does not account for issues such as deposition rate or initial velocity, but serves to quantify the potential errors of using flume data for direct extrapolation to field applications.
\end{abstract}

\section{Introduction}

A summary of thickened tailings projects around the world by Williams et al. (2008) showed that typical beach slope angles were around 2 to $3 \%$, with $5 \%$ rarely being achieved. However, there continues to be an expectation that much steeper beach slopes can be achieved on a consistent basis. Part of the reason for this unrealistic expectation may be due to the use of narrow laboratory flumes for predicting beach slopes.

As thickening technology improves, it is likely that the achievable slope angles will increase and it is important to be able to predict these slope angles with some degree of certainty. If, for example, a central discharge method were planned for a flat area with an allowable circular footprint of $0.78 \mathrm{~km}^{2}$ (corresponding to a radius of $1 \mathrm{~km}$ ) and the predicted slope angle was 3\%, the allowable height of the facility would be $30 \mathrm{~m}$. However, if the beach slope actually achieved on site were only $2 \%$, the footprint for a central height of $30 \mathrm{~m}$ would be $1.77 \mathrm{~km}^{2}$ (with a radius of $1.5 \mathrm{~km}$ ). Alternatively, if the footprint remained unchanged at $0.78 \mathrm{~km}^{2}$, the allowable maximum height would be only $20 \mathrm{~m}$. Either way, the implications for the mining operation would be severe. Small differences between predicted and actual beach angles are thus extremely important in a facility of this sort because the absolute values are themselves small. The attractiveness of using simple laboratory flumes for predicting beach slopes is thus understandable, but must be used with caution, as emphasised in this paper.

\section{Techniques for predicting beach slopes}

One of the techniques favoured for the prediction of beach slope angles is a laboratory flume test (Küpper et al., 1992). These tests, carried out in flumes that are typically of the order of $2 \mathrm{~m}$ long, $0.15 \mathrm{~m}$ wide and about $0.5 \mathrm{~m}$ high, have been used successfully for many years for testing conventional mine tailings (the term conventional mine tailings is used in this paper to represent tailings that segregate upon deposition).

\subsection{Predicting beach slope angles of conventional tailings using flume tests}

Conventional tailings, at low solids concentrations are prone to segregation, with the coarser particles predominantly confined to the point of deposition and the finer particles close to the toe of the profile. Building on the work of Melent'ev et al. (1973), Blight and Bentel (1983), Blight et al. (1985) and Wates (1987) it can be shown that the profiles developed in laboratory flumes could, when non-dimensionalised by the total length and total height, be scaled up to produce profiles that matched those of profiles of full-scale tailings beaches of similar material. The result is a curve with the equation relating the normalised parameters:

$$
\mathrm{h} / \mathrm{Y}=(1-\mathrm{H} / \mathrm{X})^{\mathrm{n}}
$$


Where:

$\mathrm{Y}=$ the elevation difference between the discharge point and the toe.

$\mathrm{X}=$ horizontal distance between the discharge point and the toe.

$\mathrm{H}=$ the distance of a profile point to the discharge.

$\mathrm{h}=\quad$ the elevation of a point to the discharge.

$\mathrm{n}=$ the exponent which indicates the degree of curvature.

Given the success of laboratory flume tests in predicting actual beach profiles of conventional tailings facilities, it is not surprising that they have been used for predicting beach slopes of high-density thickened tailings (Robinsky, 1979). However, as discussed by Martin et al. (2002), actual slopes on deposits of thickened tailings were always flatter than those predicted from laboratory flume tests. Flume tests certainly provide a valuable visual indication of the mode of flow of thickened tailings, but seem to be of limited value in predicting field beach slopes. The remainder of this paper discusses a likely reason for this lack of direct applicability and suggests ways in which laboratory flume tests on thickened tailings may still be meaningfully interpreted.

\subsection{Thickened tailings and the concept of yield stress}

Unlike conventional tailings, thickened tailings possess both a viscosity and a yield stress where yield stress is considered to be the stress that must be overcome in order to initiate flow or movement (e.g. in a pipeline). Although there are a number of techniques for measuring the yield stress (such as the vane test, the modified slump test, inclined plane test or a range of different rheometer configurations) it seems that the vane test has become the preferred option (Liddell and Boger, 1996). Unless otherwise indicated, all yield stress values reported in this paper were obtained using the vane test. For the prediction of the beach geometry from laboratory experiments, a two-dimensional mathematical model incorporating the shear yield stress was formulated and tested. This method is similar to that used by Palmer and Krizek (1987) except that the width of the flume as well as the shear resistance is considered.

\section{$3 \quad$ Laboratory test procedures}

\subsection{Characteristics of the tailings used}

The tailings used for this investigation were zinc, and flocculated gold and copper tailings. The basic characteristics of these materials are presented in Table 1 and the particle size distribution curves are shown in Figure 1. The rheological properties characterising these tailings have been described elsewhere (Gawu, 2004).

\section{Table 1 Properties of the tailings tested}

\begin{tabular}{llll}
\hline Tailings Type & Gold & Zinc & Copper \\
\hline Specific gravity & 2.74 & 2.77 & 2.77 \\
Liquid limit (\%) & 29 & 37 & 22 \\
Plasticity index (\%) & 3 & 1 & 4 \\
Linear shrinkage $(\%)$ & 2 & 2 & 2 \\
Clay-size content $(<2 \mu \mathrm{m} ; \%)$ & 13 & 11 & 12 \\
Sand-size content $(\%)$ & 21 & 26 & 48 \\
Fines content $(<75 \mu \mathrm{m} ; \%)$ & 79 & 74 & 52 \\
\hline
\end{tabular}




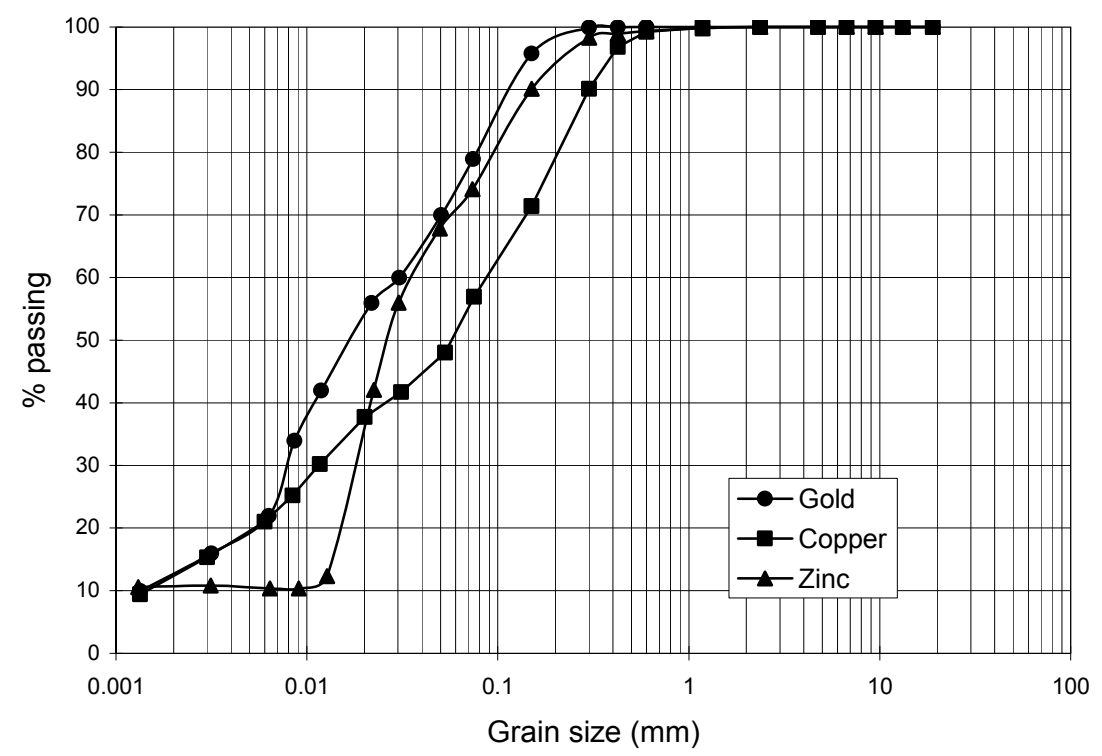

Figure 1 Particle-size distributions of tailings tested

\subsection{Flume tests}

Flume tests were performed with the zinc, copper and gold tailings at different solids concentrations. Beach slopes were measured in the laboratory after pumping tailings into a $150 \mathrm{~mm}$ wide, $500 \mathrm{~mm}$ deep, flatbottomed U-shaped flume having an effective length of $1,800 \mathrm{~mm}$. The sides of the flume were made of Perspex to enable observation of the thickened tailings during deposition, and to facilitate accurate measurement of the deposit profile and its changes due to self-weight consolidation.

In these tests, tailings were mixed in a mechanical mixer, pumped at a constant rate through a $13 \mathrm{~mm}$ diameter pipe and discharged into the front end of the flume where a metal splash plate was placed to limit the drop impact. Mixing and pumping were continued until enough material was deposited. Pumping was only stopped when the extent of flow was close to the end of the flume. The slope configurations for each tailings were measured a few minutes after deposition and also after a twenty-four hour period when selfweight consolidation had taken place. The differences were minimal and the initial value was used in the results reported in this paper. The sides of the flume restricted lateral spread and hence for modelling purposes, a two-dimensional scenario was used with the length of flow and thickness of the tailings as the only variables.

\section{$4 \quad$ Flume test results}

In Figures 2(a) and (b), the beaching and normalised profiles for zinc tailings are shown at two solids concentrations. A trend of steeper slopes with increasing solids content is evident in Figure 2(a), while in Figure 2(b) similar normalised beach geometry was obtained for different solids concentrations of the same tailings. An exponential curve with a power of 0.76 was found to give a good fit. The conventional tailings examined by Blight (1987) all gave exponents greater than 1, indicating that the profiles were "concave up", whereas with the thickened tailings, profiles are 'concave down'. A well-defined master profile can be thus obtained for thickened tailings, although there is certainly more deviation than was obtained with conventional tailings (e.g. Blight and Bentel, 1983). A similar observation was made with the gold tailings, where the exponent $\mathrm{n}$ was 0.65 . However, this observation is of little value since, as mentioned earlier, the beach slopes predicted in this way are not representative of those measured in the field for the same material. They are always steeper.

To examine the effect the volume of material deposited has on the profile formation, four profiles were measured at the same solids concentration. Figure 3 shows the distance of flow along the beach and the thickness at the discharge point as functions of the volume of tailings pumped for the same solids concentration. The curves show that the "tongue" and the height at the discharge point increases with increasing volume of tailings pumped. The corresponding normalised profiles in Figure 4 show a similar 
profile development, in terms of dimensionless parameters, that is relatively independent of the volume of the high-density zinc tailings pumped. The exponent $\mathrm{n}$ for the fitted curve had a value of 0.65 .

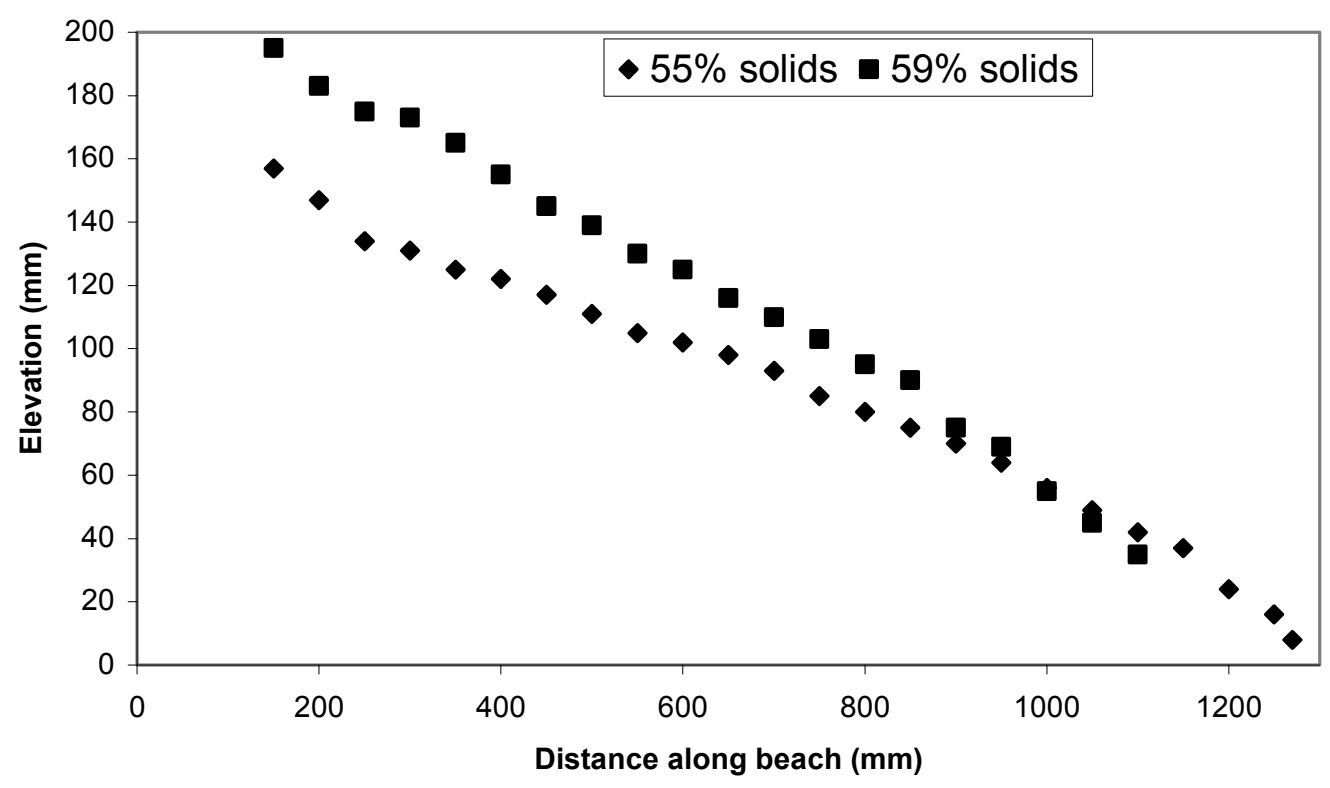

(a)

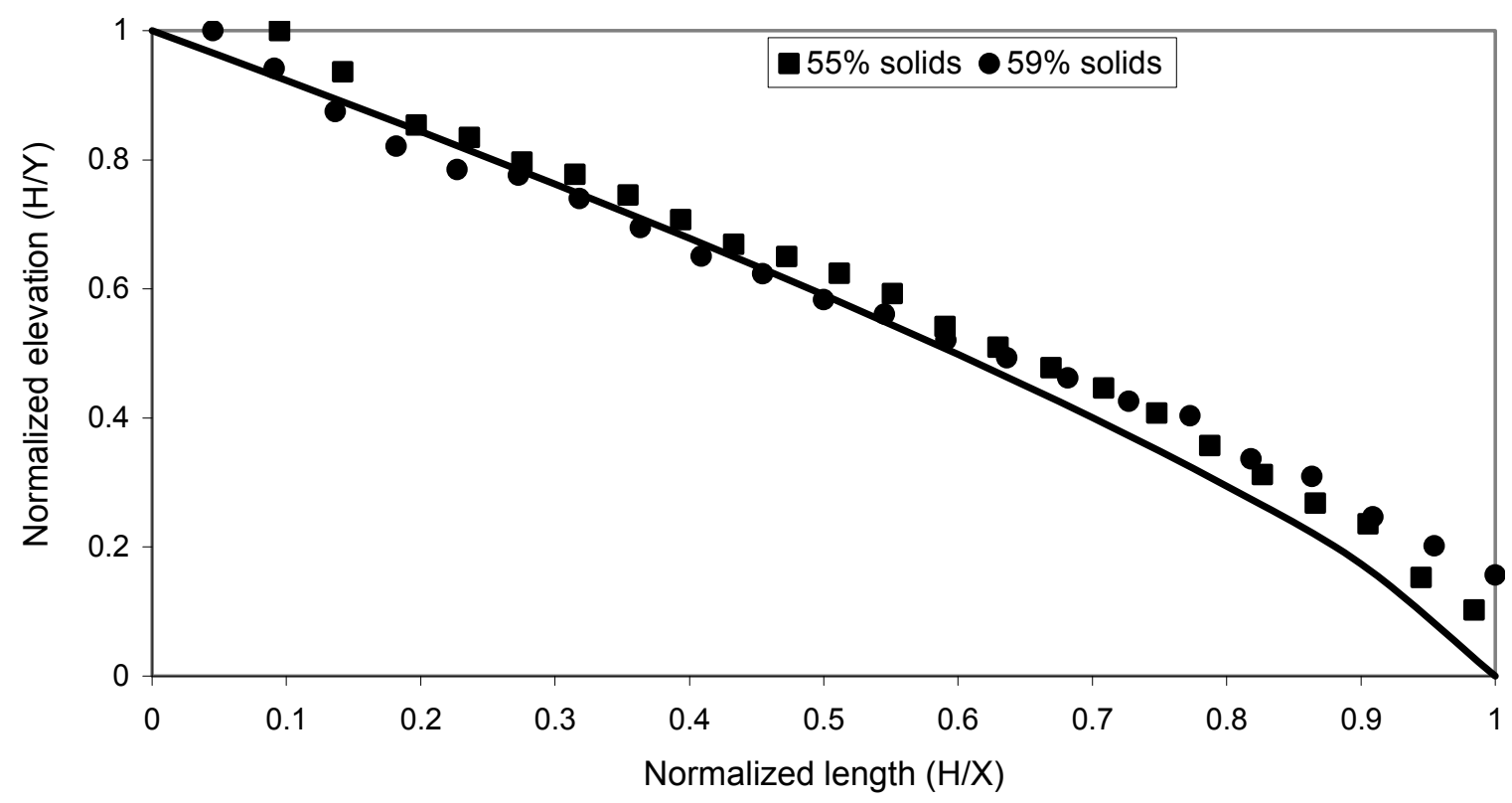

(b)

Figure 2 Flume test results for zinc tailings, showing: (a) beach profiles for two different solids concentrations; and (b) normalised profiles 


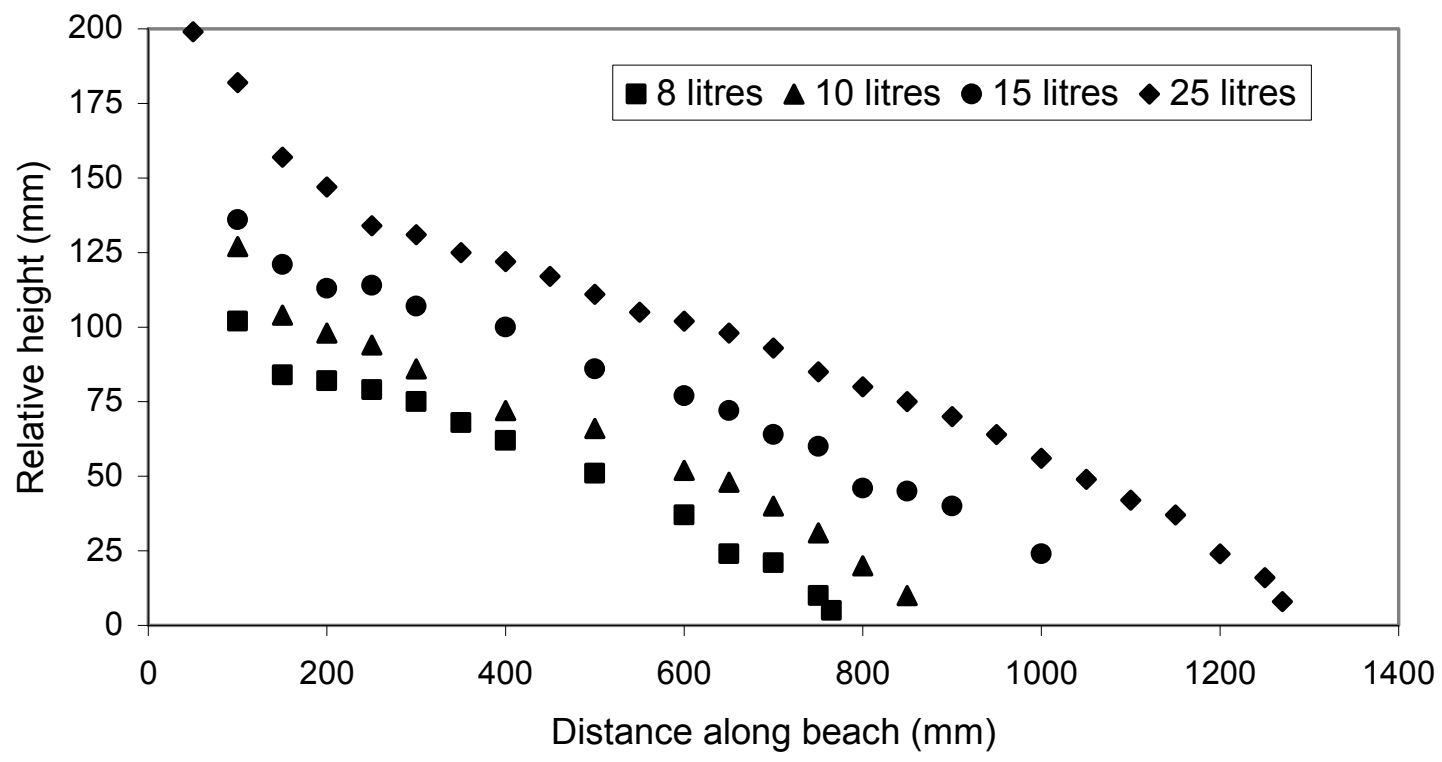

Figure 3 Profile development with volume of deposited zinc tailings (solids concentration $=\mathbf{5 5 \%}$ )

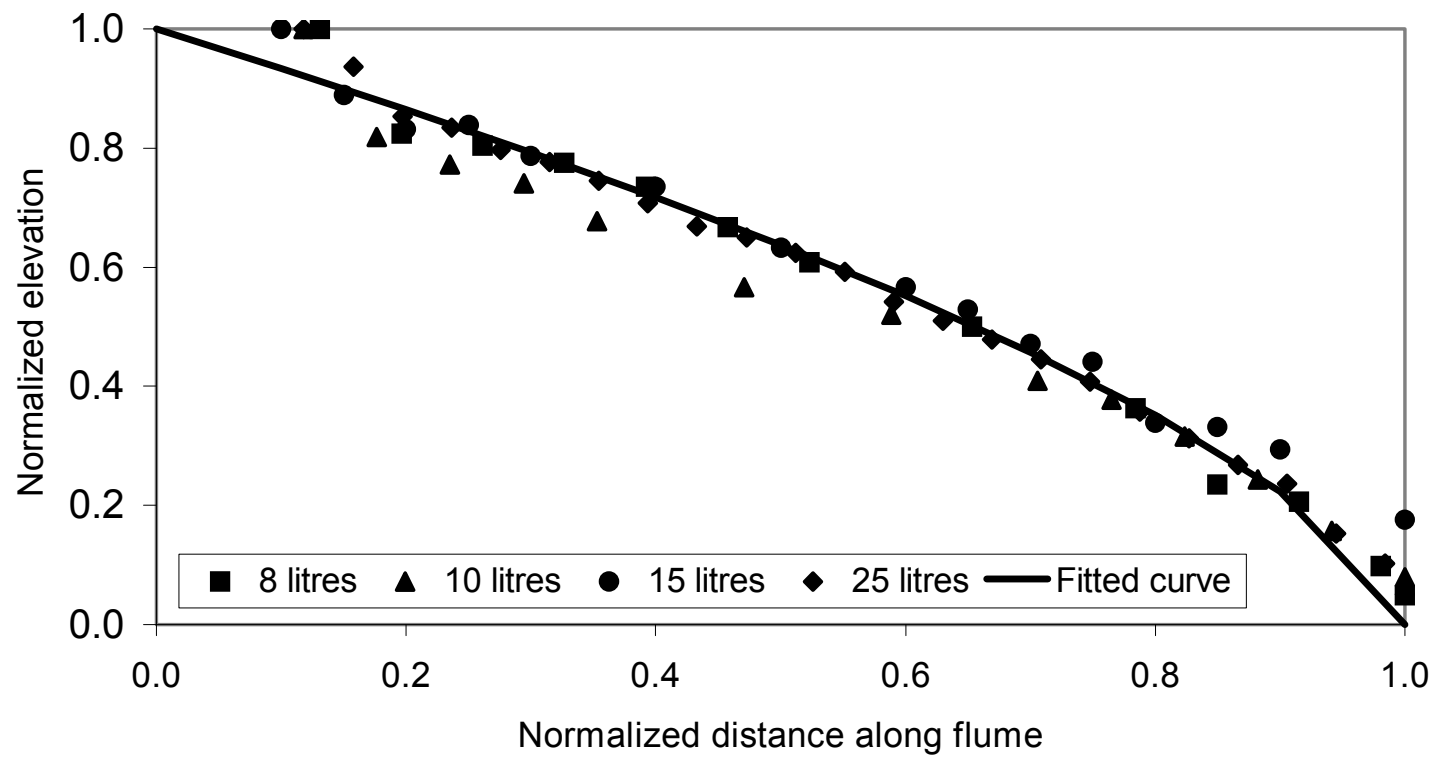

Figure 4 Normalised profiles for zinc tailings at $55 \%$ solids concentration

\section{$5 \quad$ Numerical model}

As deposition of the thickened slurry takes place in a flume, there is a build up of head for a period depending on the discharge rate, the concentration and the yield stress. Thereafter, the material slumps and flows uniformly until an equilibrium of forces acting on the slurry is established. The shear resistance from the bottom and walls of the flume resist flow and hence need consideration in formulating an appropriate model for evaluating the final shape of deposited slurry. The shear yield stress is a suitable shear resistance parameter since flow of yield stress materials, like thickened tailings, only begins after the yield stress is exceeded. In addition, the shear yield stress appears to be an all-inclusive parameter as previously explained. The model considered here only uses the shear yield stress of the materials tested.

The rationale, which is a key assumption in this paper, is that when material stops flowing in the flume it is only the yield stress that resists the body forces of the tailings. As the shear rate drops to zero, the contribution of viscosity to the forces resisting flow of the thickened tailings also drops to zero. The minimum mobilised force occurs when the shear rate (or flow rate) is zero and it is argued that this value 
thus governs the profile developed in a flume test. It is clear (e.g. Chanson et al., 2004) that the profile developed during flow is a much more complex function of yield stress and viscosity than has been assumed in the current paper. However, as will be shown later, the model developed in the current paper explains the observed discrepancies between flume and field measured beach slopes and provides a very useful estimate of full-scale beach slopes. The approach is an extension of one used previously to predict depths and rates of flow of tailings after escaping from a breached tailings impoundment (Blight et al., 1981; Blight and Fourie, 2005).
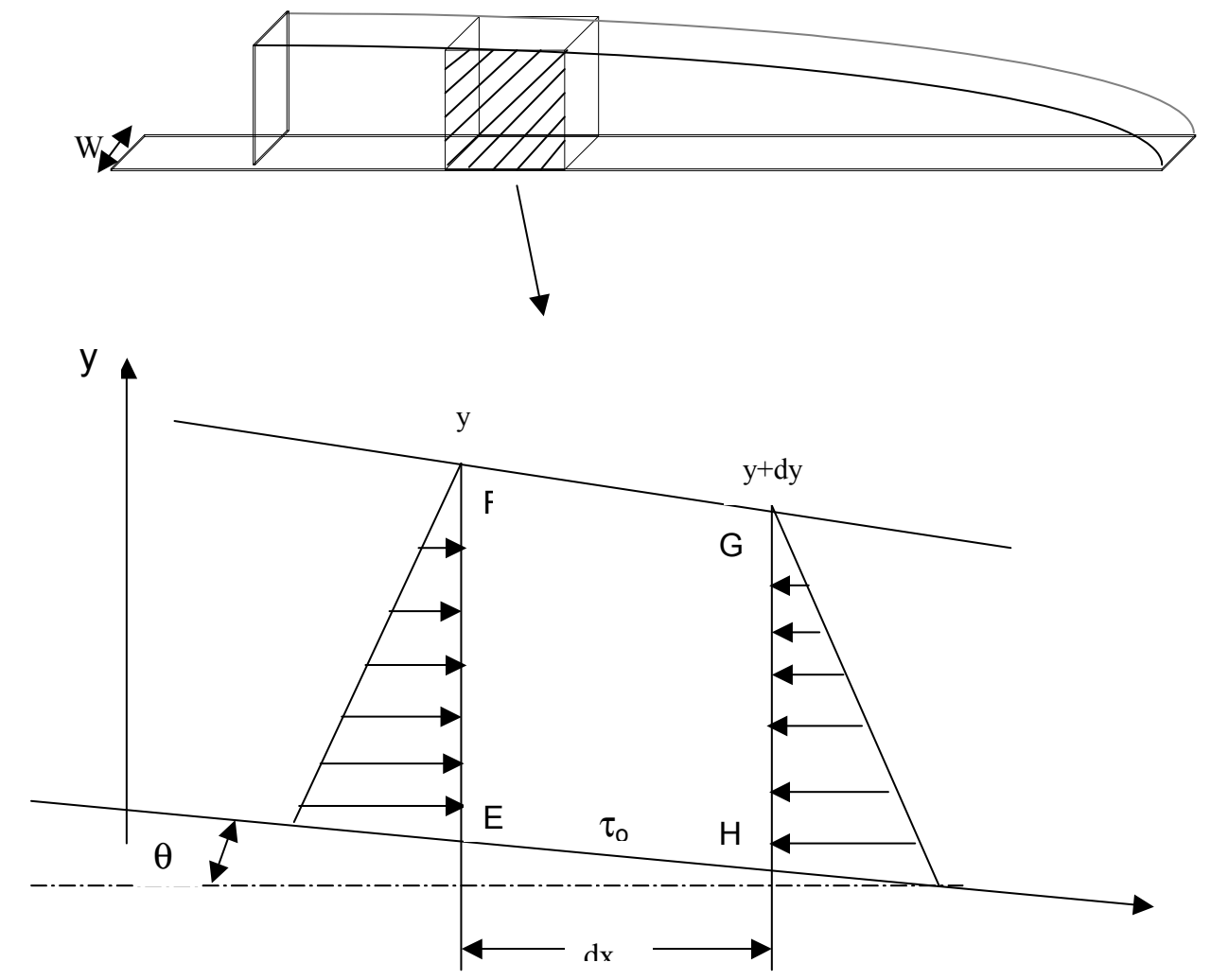

Figure 5 Sketch of a control volume for flow in a flume with vertical walls

For open channel flow in a rectangular channel, a relationship can be established between the driving and resisting forces acting on a control volume as shown in Figure 5. The development of such a relationship involves a number of simplifying assumptions including the following:

- The flow is one-dimensional.

- The slope, $\theta$, of the base of the flume is constant over the entire flow distance and the thickness of the deposited material is also constant in the direction perpendicular to the line of flow.

- The channel has a constant width, w.

- The pressure within the deposited material is hydrostatic.

The forces acting on the control volume, EFGH in the $\mathrm{x}$-direction are:

1. The net hydrostatic pressure, $F_{1}\left(f_{1}-f_{r}\right)$, acting on the right and left sides of the control volume.

2. The mass of the element EFGH is responsible for the body force, $F_{2}$.

3. The shearing resistance forces at the bottom and two vertical sides of the rectangular channel are responsible for force, $\mathrm{F}_{3}$.

Force $F_{1}$ can be written as shown in Equation (2):

$$
F_{1}=\left(f_{1}-f_{r}\right)=\frac{1}{2} \cdot \rho \cdot g \cdot w \cdot y^{2} \cdot \cos (\theta)-\frac{1}{2} \cdot \rho \cdot g \cdot w \cdot(y+d y)^{2} \cdot \cos (\theta)
$$


Where:

$\mathrm{g}=$ gravitational acceleration.

$\rho \quad=\quad$ tailings density.

$$
F_{2}=\rho \cdot g \cdot A \cdot d x \cdot \sin (\theta)
$$

Where:

A $=\quad$ cross-sectional area given by $\frac{1}{2} \cdot \mathrm{w} \cdot(2 \cdot \mathrm{y}+\mathrm{dy})$.

$$
\mathrm{F}_{3}=\tau_{\mathrm{o}} \cdot \mathrm{P}_{\mathrm{w}} \cdot \mathrm{dx}
$$

Where:

$\mathrm{P}_{\mathrm{w}}=\quad$ perimeter of the wetted surface given by $(\mathrm{w}+2 \mathrm{y}+\mathrm{dy})$.

$\tau_{\mathrm{o}} \quad=\quad$ average shear yield stress.

Assuming that $\mathrm{dy} \cdot \mathrm{dx} \approx \mathrm{dy}^{2} \approx 0$, each of the force components becomes:

$$
\begin{gathered}
\mathrm{F}_{1}=-\rho \cdot \mathrm{g} \cdot \mathrm{y} \cdot \mathrm{w} \cdot \mathrm{dy} \cdot \cos (\theta) \\
\mathrm{F}_{2}=\rho \cdot \mathrm{g} \cdot \mathrm{y} \cdot \mathrm{w} \cdot \mathrm{dx} \cdot \sin (\theta) \\
\mathrm{F}_{3}=\tau_{\mathrm{o}} \cdot(\mathrm{w}+2 \mathrm{y}) \cdot \mathrm{dx}
\end{gathered}
$$

By equating the driving and resisting forces, the relationship can be re-written as follows:

$$
d x=\frac{\rho \cdot g \cdot w \cdot y \cdot \cos (\theta)}{\rho \cdot g \cdot w \cdot y \cdot \sin (\theta)-\tau_{0}(w+2 \cdot y)} d y
$$

By separating the variables, Equation (8) can be solved to obtain a relationship relating the depth of flow, y, the flume width, $\mathrm{w}$, and the distance from the origin, $\mathrm{x}$, to the shear yield stress, $\tau_{\mathrm{o}}$, and the slope of the flume as summarised below:

$$
\begin{aligned}
& \frac{1}{\rho \cdot g \cdot w} d x=\left[\frac{\cos \theta}{\rho \cdot g \cdot w \cdot \sin (\theta)}+\frac{\frac{\tau_{0} \cdot w \cdot \cos (\theta)}{\rho \cdot g \cdot w \cdot \sin (\theta)-2 \cdot \tau_{o}}}{\left(\rho \cdot g \cdot w \cdot \sin (\theta)-2 \cdot \tau_{o}\right) \cdot y-\tau_{0} \cdot w}\right] d y \\
& \frac{\left[\rho \cdot g \cdot w \cdot \sin (\theta)-2 \cdot \tau_{o}\right]}{\rho \cdot g \cdot w \cdot \cos (\theta)} d x=\left(1+\frac{\tau_{o} \cdot w}{\left(\rho \cdot g \cdot w \cdot \sin (\theta)-2 \cdot \tau_{o}\right) \cdot y-\tau_{o} \cdot w}\right) d y
\end{aligned}
$$

Integrating between two arbitrary points gives:

$$
\begin{aligned}
& \left.\frac{\left[\rho \cdot g \cdot w \cdot \sin (\theta)-2 \cdot \tau_{0}\right] \cdot x_{1}}{\rho \cdot g \cdot w \cdot \cos (\theta)}=y_{1}+\frac{\tau_{0} \cdot w}{\rho \cdot g \cdot w \cdot \sin (\theta)-2 \cdot \tau_{0}} \ln \mid \rho \cdot g \cdot w \cdot \sin (\theta)-2 \cdot \tau_{0}\right] \cdot y_{1}-\tau_{0} \cdot w \mid+K \\
& \left.\frac{\left[\rho \cdot g \cdot w \cdot \sin (\theta)-2 \cdot \tau_{0}\right] \cdot x_{2}}{\rho \cdot g \cdot w \cdot \cos (\theta)}=y_{2}+\frac{\tau_{0} \cdot w}{\rho \cdot g \cdot w \cdot \sin (\theta)-2 \cdot \tau_{0}} \ln \mid \rho \rho g \cdot w \cdot \sin (\theta)-2 \cdot \tau_{0}\right] \cdot y_{2}-\tau_{0} \cdot w \mid+K
\end{aligned}
$$

Where:

$\mathrm{K}=$ constant of integration. 
Subtracting these two equations results in the following:

$$
\begin{aligned}
& \mathrm{y}_{1}-\mathrm{y}_{2}+\frac{\tau_{\mathrm{o}} \cdot \mathrm{w}}{2 \cdot \tau_{\mathrm{o}}-\rho \cdot \mathrm{g} \cdot \mathrm{w} \cdot \sin (\theta)} \cdot \ln \left|\frac{\left[2 \cdot \tau_{\mathrm{o}}-\rho \cdot \mathrm{g} \cdot \mathrm{w} \cdot \sin (\theta)\right] \cdot \mathrm{y}_{2}+\tau_{0} \cdot \mathrm{w}}{\left[2 \cdot \tau_{0}-\rho \cdot \mathrm{g} \cdot \mathrm{w} \cdot \sin (\theta)\right] \cdot \mathrm{y}_{1}+\tau_{0} \cdot \mathrm{w}}\right| \\
& =\frac{\left[2 \cdot \tau_{\mathrm{o}}-\rho \cdot \mathrm{g} \cdot \mathrm{w} \cdot \sin (\theta)\right]\left(\mathrm{x}_{2}-\mathrm{x}_{1}\right)}{\rho \cdot \mathrm{g} \cdot \mathrm{w} \cdot \cos (\theta)}
\end{aligned}
$$

The condition for Equation (13) to be valid is:

$$
\tau \neq \frac{1}{2} \cdot \rho \cdot \mathrm{g} \cdot \mathrm{W} \cdot \sin (\theta)
$$

Otherwise the solution of Equation (8) between two arbitrary points simplifies to:

$$
\mathrm{y}_{1}^{2}-\mathrm{y}_{2}^{2}=\frac{2 \cdot \tau_{0}\left(\mathrm{x}_{2}-\mathrm{x}_{1}\right)}{\rho \cdot \mathrm{g} \cdot \cos (\theta)}
$$

Equation (13) was used to predict the tailings profile in a laboratory-sized flume following a method described by Palmer and Krizek (1987). The flume was first divided into small equal reaches, (x2 - x1), over which the slope was assumed to be constant. Thereafter, the measured height of the tailings at the discharge point, y1, was noted and Equation (13) was solved by iteration to obtain $\mathrm{y} 2$, the height at $\mathrm{x} 2$. The same procedure was applied for the next reach and y2 was used as the 'starting point'. The process was repeated until the solution was close to zero in which case the extent of flow was assumed to be fully defined.

The input parameters required to utilise this model are the width and inclination of the flume, the initial height at the point of deposition, and the density and shear yield stress of the tailings. The shear yield stress was determined by the vane procedure (Gawu and Fourie, 2004), the density of the tailings was deduced from its solids concentration (and checked during flume tests) and the use of phase relations; and finally the slope of the flume was calculated from the height above a datum at the head and toe.

\subsection{Comparison of model results with experiments}

Figure 6 compares the theoretical prediction for flocculated gold tailings at a solids concentration of 55\% with values measured using fully sheared tailings. The shear yield stress after flocculation and dewatering was determined to be $31 \mathrm{~Pa}$ prior to continuous mixing. The model generated a profile that underestimated the longitudinal extent of flow when a yield stress value of $31 \mathrm{~Pa}$ was used. With a yield stress value of $20 \mathrm{~Pa}$, which corresponded to the fully sheared value, however, the theoretical prediction agreed very well with the measured profile. The $36 \%$ reduction in the shear yield stress value was due to the "breakdown" property that is exhibited by the flocculated gold tailings as previously noted.

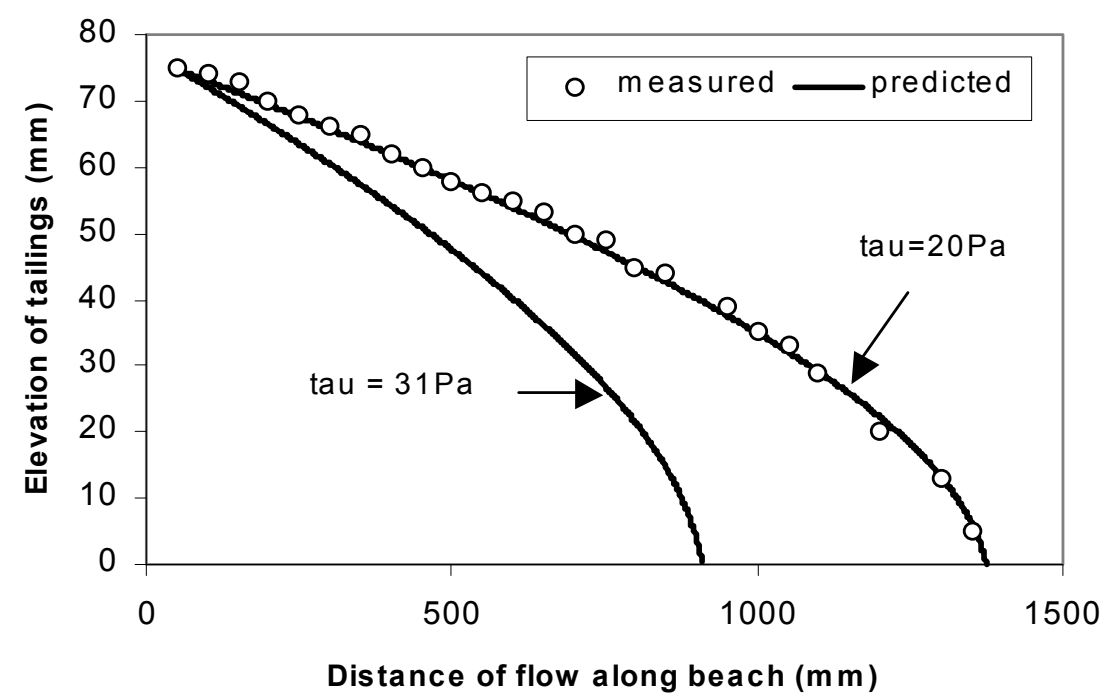

Figure 6 Comparison between predicted and measured flume profiles for gold tailings at $55 \%$ solids concentration (with base of flume horizontal) 
The profile measured for flocculated gold tailings at 59\% solids concentration was also compared with the theoretical prediction. The yield stress value for this solids concentration was determined to be $57 \mathrm{~Pa}$ prior to shearing. The fully sheared yield stress value was $32 \mathrm{~Pa}$ and this was used for the prediction shown in Figure 7. This is a further manifestation of the breakdown property. An appropriate yield stress value of the tailings during deposition is therefore required for an accurate prediction to be made. Hence, if the tailings are likely to be subjected to a high degree of shearing during transportation to the tailings dam, the material tested in the laboratory must be subjected to a similar degree of shearing prior to testing.

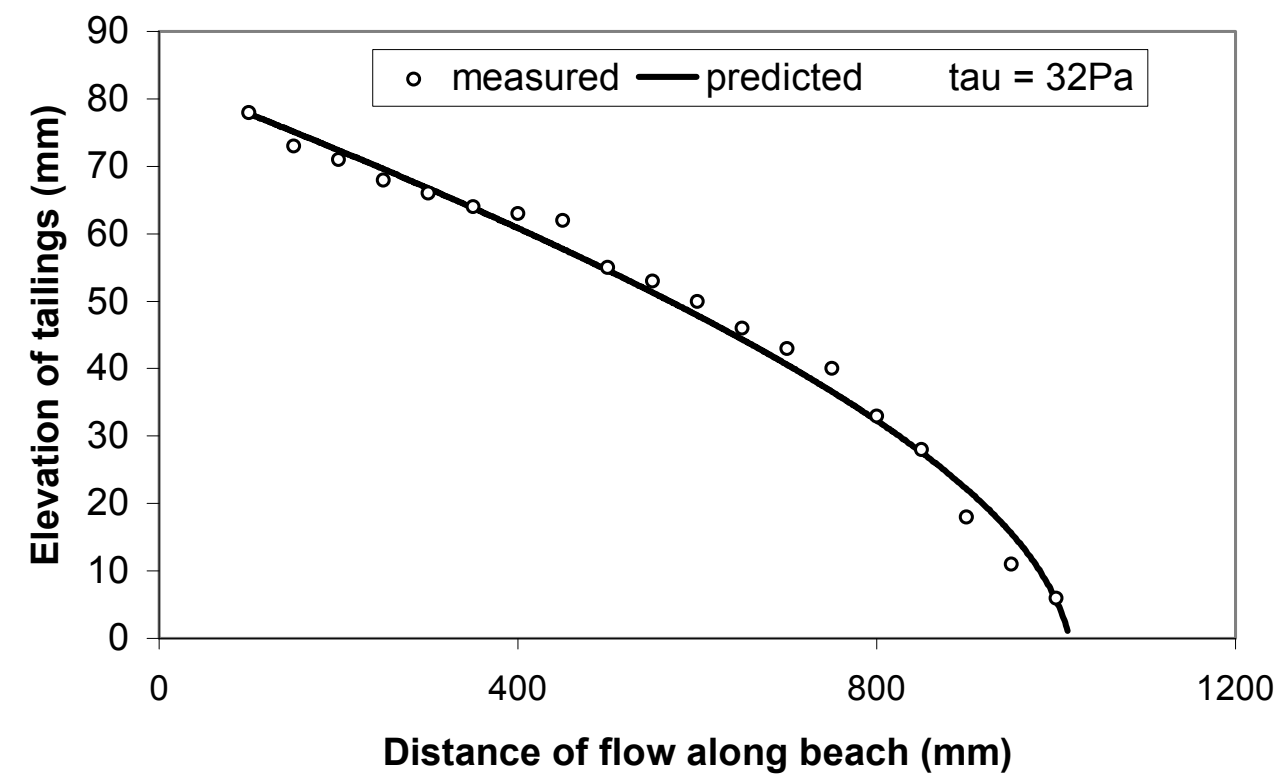

Figure 7 A comparison of measured flume profile for gold tailings at $59 \%$ solids with the theoretically predicted one

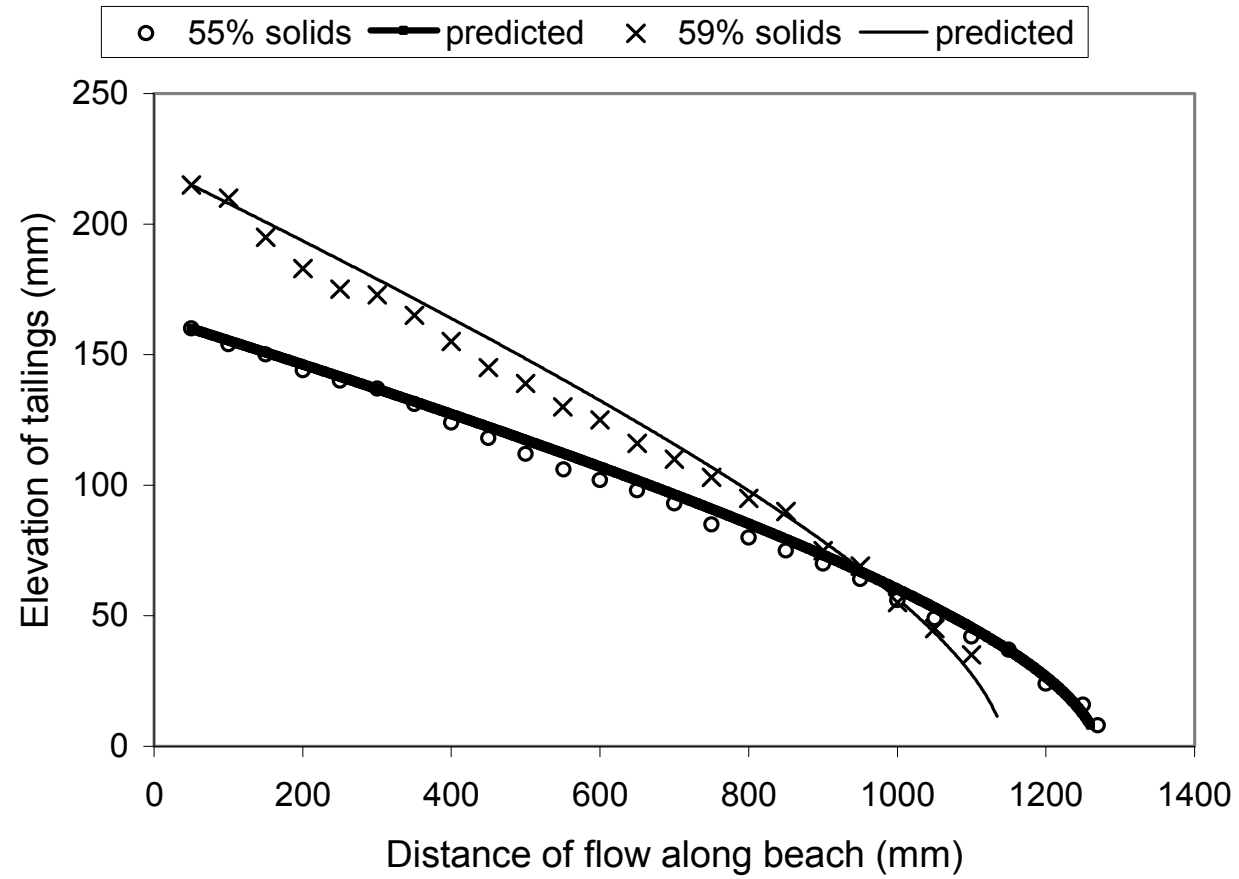

Figure 8 Comparison between predicted and measured flume profiles for high-density zinc tailings at 55 and $59 \%$ solids concentrations

Further tests were carried out with high-density zinc tailings and the results are shown in Figure 8 . The predicted and measured profiles were similar when the appropriate yield stress values were used. Figure 9 
shows the profiles measured for flocculated copper tailings in a flume inclined at $5 \%$. The 5\% inclination was to simulate a field slope of about $2.86^{\circ}$. The predicted results show a reasonably good estimate of the measured profiles at the two solids concentrations tested. The values of yield stress were independently determined with the vane method using material that had been mixed for the same time as in the flume tests and were $31 \mathrm{~Pa}$ and $90 \mathrm{~Pa}$ at 60 and $70 \%$ solids, respectively.

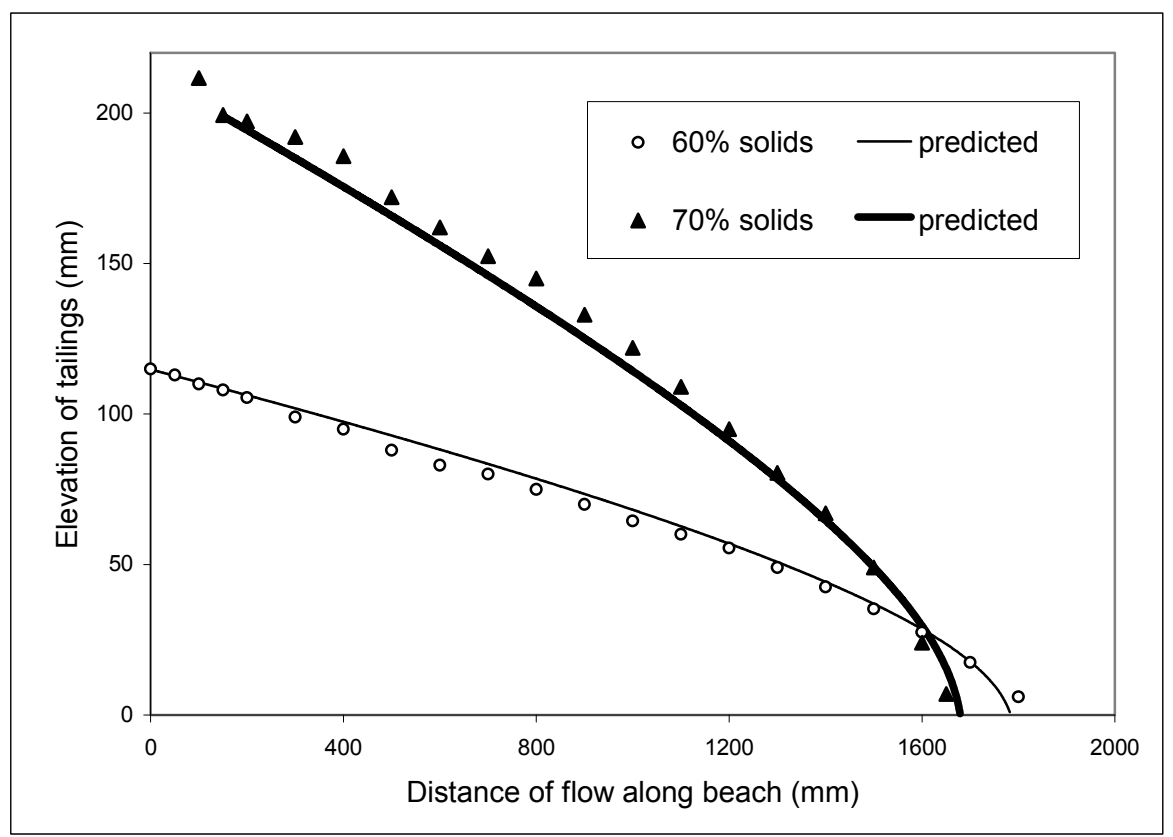

Figure 9 A comparison of measured and predicted flume profiles for copper tailings at 60 and $70 \%$ solids concentration (flume inclined at $5 \%$ )

\subsection{Influence of flume width}

The predicted effects of flume width variation on the average slope angle of deposited tailings are shown in Figure 10 for gold and Figure 11 for copper tailings at thicknesses of 115 and $75 \mathrm{~mm}$, respectively.

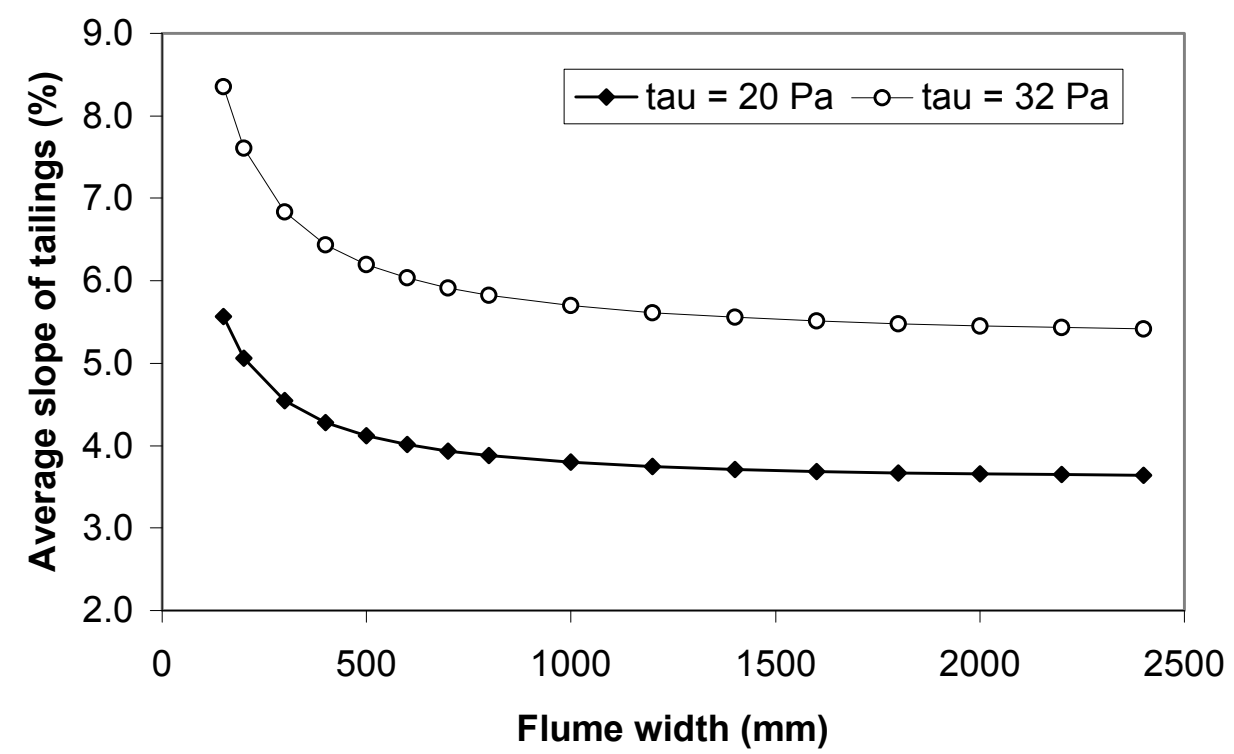

Figure 10 The effect of flume width on the slope angle for two yield stress values of gold tailings 


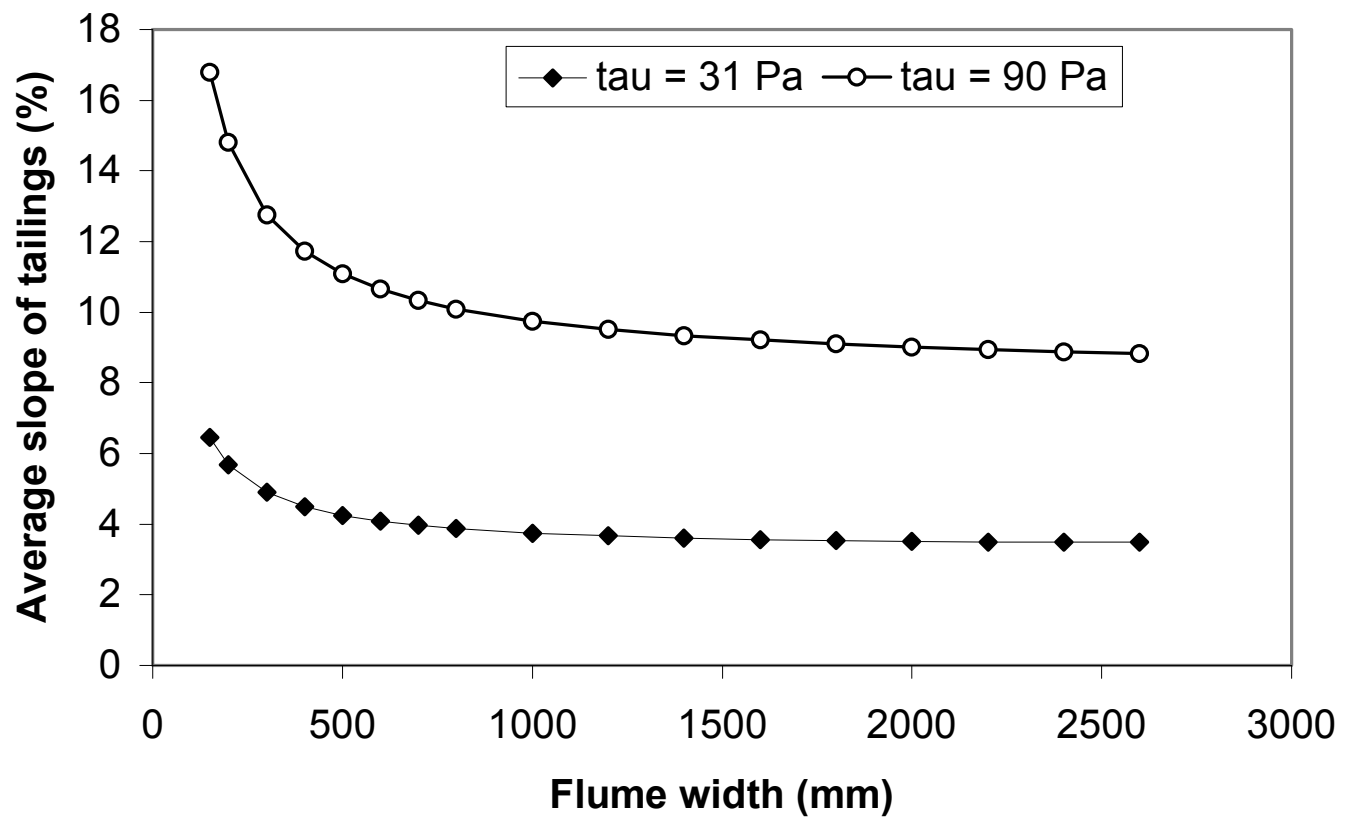

Figure 11 The effect of flume width on the slope angle of copper tailings for yield stress values of $31 \mathrm{~Pa}$ and $90 \mathrm{~Pa}$ (base of flume inclined at 5\%)

From the results of this analysis, it can be seen that the slope decreases with increasing flume width. The decrease is rapid for the gold and copper tailings up to a flume width of $500 \mathrm{~mm}$, after which the decrease becomes gradual. The angle of slope is practically independent of the flume width at values of flume width greater than $1,600 \mathrm{~mm}$. This observation is independent of the tailings type as well as the solids concentration. Conditions in the field will be different from that in a flume, with material flowing laterally as well as longitudinally.

Further illustration of the limitations of using a laboratory flume is shown by comparing the laboratory results in Figure 10, where a slope of 3.7\% is predicted for a yield stress of $20 \mathrm{~Pa}$. This can be contrasted with the field experience of an operation such as that at Alcoa in Australia, where a consistent yield stress of $25-50 \mathrm{~Pa}$ is produced by their thickener, but the beach slope achieved is only in the order of $1.2 \%$ (Williams et al., 2008). Clearly, other influences such as yield stress variation and dynamic flow conditions have an important effect on the equilibrium beach slope; however, these factors cannot be reproduced in a laboratory flume. Even if due account is taken of the effect of side-wall friction on the predicted beach slope, laboratory flume tests are still likely to overestimate these slopes.

\subsection{Influence of height at the point of deposition}

Figure 12 shows the distance of flow along the beach as a function of the thickness at the discharge point for zinc tailings at $55 \%$ solids concentration in a $150 \mathrm{~mm}$ wide flume. From the model results, it can be seen that the extent of flow increases with increasing initial height and a consequent increasing volume, similar to the measurements taken with zinc tailings in Figure 4. On a normalised scale, a unique profile with a degree of curvature of 0.65 that is independent of the height at the point of deposition was found. This value is the same as that obtained when a curve was fitted to the experimental data.

The effect of the initial height at the point of deposition on the average slope angle was also modelled for copper tailings at $70 \%$ solids concentration with the base of the flume inclined at $5 \%$. This general trend is shown in Figure 13. The average slope generally decreases with increasing initial height; the decrease is sharp for low initial heights and gentler at higher initial heights. This trend implies that as deposition at the same point increases, the final beach slope angle decreases indicating that material at the toe is subjected to a greater force from the increased initial height. The extent of flow thus increases. 


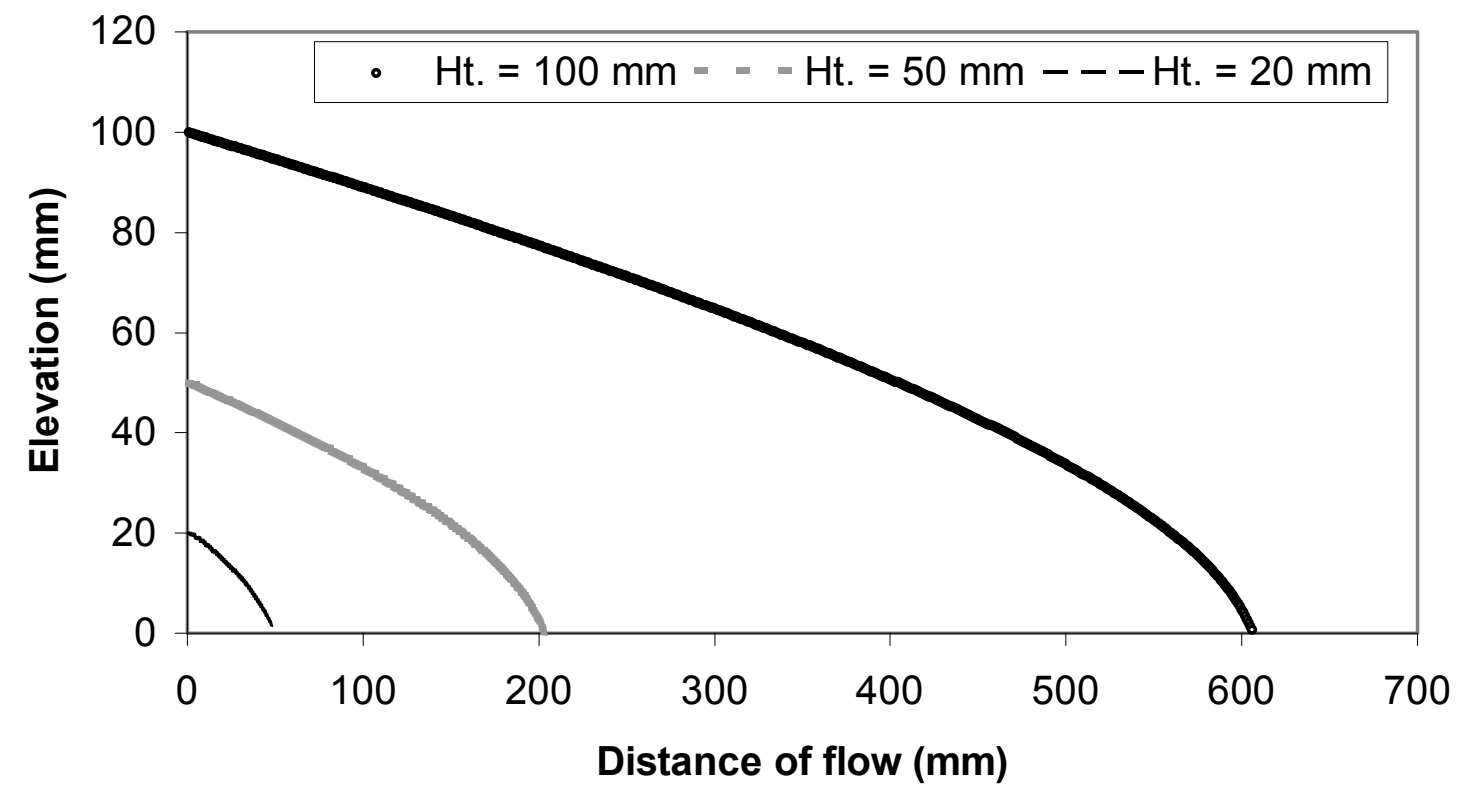

Figure 12 Profile development as a function of thickness at the point of deposition for zinc tailings at $\mathbf{5 5 \%}$ solids concentration

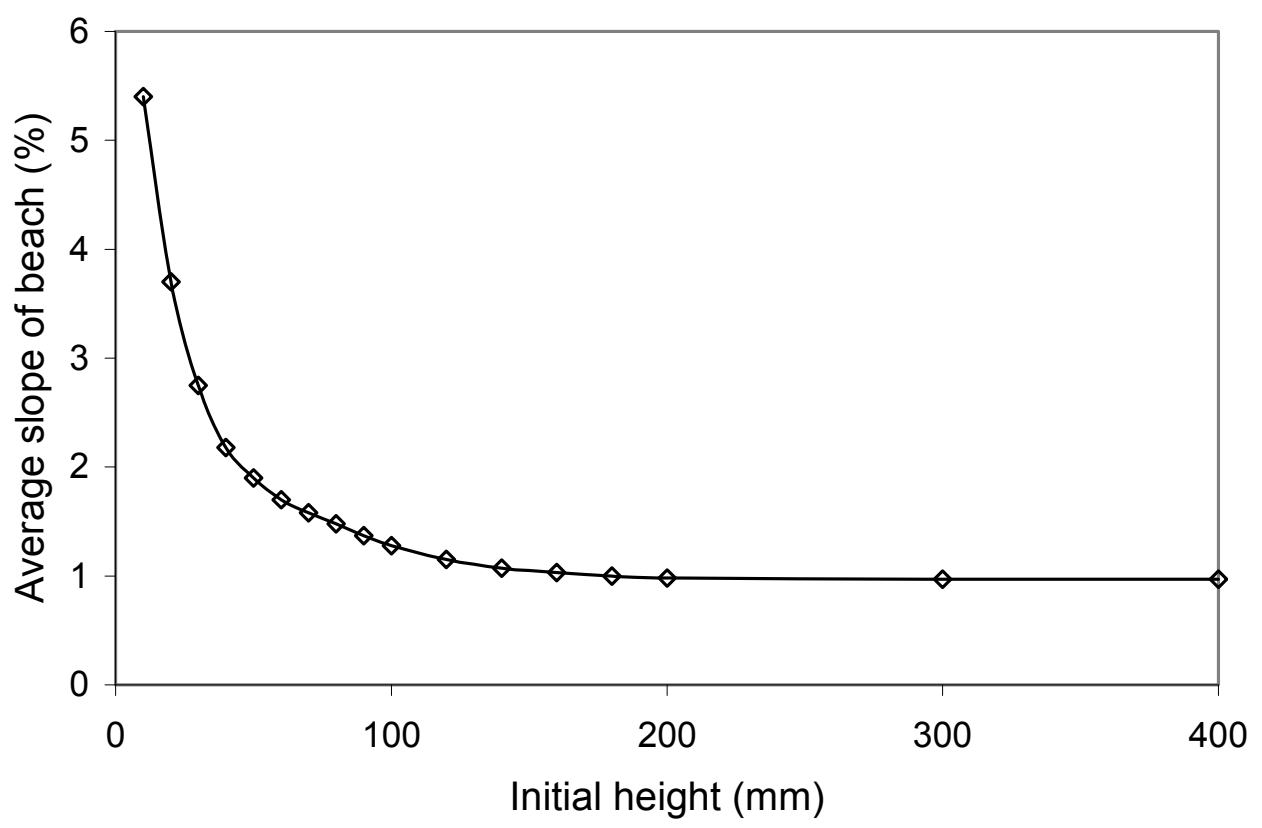

Figure 13 Average beach slope versus height at deposition point for copper tailings at $70 \%$ solids concentration (Base of flume inclined at 5\%)

\section{Conclusions}

A laboratory-size flume of width $150 \mathrm{~mm}$ was used in deposition experiments that culminated in the development of a mathematical model that was tested on three tailing types. Using this model to analyse flow of thickened tailings in a narrow laboratory flume illustrated a number of important points:

- Laboratory flume tests cannot be used for predicting the slope of thickened tailings beaches without including the effect of side-wall friction. Ignoring this effect results in predicted slope angles that are significantly steeper than those achieved in the field. This effect is exacerbated if thin layers are used in the flume test, as even steeper slopes will be measured. 
- It may be possible to make sensible predictions of beach slopes based on only yield stress and slurry density using the simple equation of Blight and Bentel (1983). This simple approach also facilitates evaluations of the sensitivity of factors such as layer thickness on the beach slope angle. This could assist tailings disposal facility operators to plan deposition sequences to maximise beach slope development. It clearly needs to be evaluated against field behaviour for a range of tailings types, ensuring that a representative value of yield stress is used in the analysis. Since some thickened tailings have the tendency to 'breakdown' as a result of shearing, it is important to determine the structural state and hence the yield stress during deposition of the pumped tailings.

- The variation in thickener output (and thus the yield stress) may well be the most significant factor governing the beach slopes achieved on site. Rather than emphasising a complex model that accounts for three-dimensional flow effects, more attention could be given to producing predictions that take into account the most likely variation of thickener output.

\section{Acknowledgements}

The authors wish to thank the Government of Ghana and the University of the Witwatersrand for supporting the first author during his studies.

\section{References}

Blight, G.E. (1987) The concept of the master profile for tailings dam beaches, in Proceedings International Conference on Mining and Industrial Waste Management, Johannesburg, pp. 95-100.

Blight, G.E. and Bentel, G.M. (1983) The behaviour of mine tailings during hydraulic deposition, Journal of the South African Institute of Mining and Metallurgy, 83 (4), pp. 73-86.

Blight, G.E. and Fourie, A.B. (2005) Catastrophe revisited - disastrous flow failures of mine and municipal solid waste, Geotechnical and Geological Engineering, 23(3), pp. 219-248.

Blight, G.E., Robinson, M.J. and Diering, J.A.C. (1981) The flow of slurry from a breached tailings dam, Journal of the South African Institution of Mining and Metallurgy, 81 (1), pp. 1-8.

Blight, G.E., Thomson, R.R. and Vorster, K. (1985) Profiles of hydraulic-fill tailings beaches, and seepage through hydraulically sorted tailings, Journal of the South African Institution of Mining and Metallurgy, 85(5), pp. 157-161.

Chanson, H., Coussot, P., Jarny, S. and Tocquer, L. (2004) A study of dam break wave of thixotropic fluid: bentonite surges down an inclined plane, Research report, Department of Civil Engineering, University of Queensland.

Gawu, S.K.Y. (2004) Characterizing thickened tailings for safe environmental surface placement, PhD Thesis, University of the Witwatersrand, Johannesburg, South Africa.

Gawu, S.K.Y. and Fourie, A.B. (2004) Assesment of the modified slump test as a measure of the yield stress of highdensity thickened tailings, Canadian Geotechnical Journal, 41(1), pp. $39-47$.

Küpper, A.A.G., Morgenstern, N.R. and Sego, D.C. (1992) Comparison between various flume tests used for hydraulicfill studies, Canadian Geotechnical Journal, 29, pp. 418-425.

Liddell, P.V. and Boger, D.V. (1996) Yield stress measurement with the vane, Journal of Non-Newtonian Fluid Mechanics, 63, pp. 235-261.

Martin, T.E., Davies, M.P., Rice, S., Higgs, T. and Lighthall, P.C. (2002) Stewardship of tailings dams, Mining, Minerals and Sustainable Development Report No. 20, International Institute for Environment and Development, London.

Melent'ev, V.A., Kolpashnikov, N.P. and Volnin, B.A. (1973) Hydraulic fill structures, Energy, Moscow (English translation of original Russian).

Palmer, B. and Krizek, R.J. (1987) Thickened slurry disposal for process tailings, in Proceedings Specialty conference Geotechnical Practice for Waste Disposal, Michigan, American Society of Civil Engineers, pp. 728-743.

Robinsky, E.I. (1979) Tailing disposal by the thickened discharge method for improved economy and environmental control in tailings disposal today, in Proceedings 2nd International Tailing Symposium, Denver, Colorado, May 1978, Vol. 2, Miller Freeman Publications, Inc., San Francisco, California, USA, pp. 75-92.

Wates, J.A. (1987) The effect of relative densities on beaching angles and segregation on gold and uranium tailings dams, in Proceedings International conference on Mining and Industrial Waste Management, Johannesburg, South Africa, pp. 89-93.

Williams, M.P.A., Seddon, K.D. and Fitton, T.G. (2008) Surface Disposal of Paste and Thickened Tailings - A Brief History and Current Confronting Issues, in Proceedings Eleventh International Seminar on Paste and Thickened Tailings, Australian Centre for Geomechanics, Perth, Australia, pp. 143-164. 
